\title{
Assessment of Anticholinergic Use After Fading of BTX-A Effects in Refractory Idiopathic Overactive Bladder: A Prospective Blinded Randomized Trial
}

\author{
M.A. Elbaset ${ }^{1}$, Diaa-Eldin Taha ${ }^{2}$, Ahmed S. El-Hefnawy ${ }^{1}$, Mohamad H. Zahran ${ }^{1}$, A.A Shokeir ${ }^{1}$ \\ ${ }^{1}$ Urology Department, Urology and Nephrology Center, Mansoura University, Mansoura, Egypt \\ ${ }^{2}$ Urology Department, KafrELshiekh University, KafrELshiekh, Egypt
}

Purpose: To evaluate the efficacy and safety of re-treatment with anticholinergics on refractory idiopathic overactive bladder $(\mathrm{OAB})$ previously treated with intravesical botulinum neurotoxin type A (BTX-A) injections.

Methods: One hundred patients were initially managed by intravesical injections of $100 \mathrm{IU}$ of BTX-A. After the effects of BTX-A faded, patients were randomized into 2 groups: group A patients received solifenacin $(10 \mathrm{mg}$ ) for 12 weeks (study group), while group B patients received placebo treatment for 12 weeks (control group), then subsequently received solifenacin (10 $\mathrm{mg}$ ) for another 6 weeks. All patients underwent preoperative urodynamic testing. Patients were asked to complete the validated overactive bladder symptoms score (OABSS) and incontinence quality of life (I-QoL) instruments after the effects of intravesical BTX-A faded and at 12 weeks of follow-up. Univariate and multivariate analyses of the factors affecting treatment response were conducted. Results: At 12 weeks of follow-up, in group A, all OABSS items, including the total score, had improved significantly $(\mathrm{P}<0.0001)$. Group A had lower frequency and amplitude of detrusor overactivity and detrusor leak point pressure $(\mathrm{P}<0.0001, \mathrm{P}=0.03$, and $\mathrm{P}=0.01$, respectively). Cystometric capacity also increased significantly $(\mathrm{P}=0.007)$, as did all $\mathrm{I}-\mathrm{QoL}$ parameters. In a comparison of patients with failed treatment and patients with successful treatment, female sex, repeated intravesical BTX-A injections, and increased bladder capacity were statistically significant $(\mathrm{P}=0.001, \mathrm{P}=0.0001$, and $\mathrm{P}=0.002$, respectively). Repeated intravesical BTX-A injections and increased bladder capacity were independent factors predicting treatment success.

Conclusions: In patients with refractory idiopathic $\mathrm{OAB}$, reuse of anticholinergics could be an effective treatment option in patients after the effects of BTX-A fade. Repeated intravesical BTX-A injections and increased cystometric capacity could affect treatment response.

Keywords: Urinary bladder, overactive; Botulinum toxins, type A; Quality of life; Solifenacin

- Research Ethics: The study was approved by the Institutional Review Board of Institution of Mansoura University) (IRB No. R/17.07.46) and the study protocol was also recorded at clinicaltrials.gov.

- Conflict of Interest: No potential conflict of interest relevant to this article was reported.

\section{INTRODUCTION}

Overactive bladder $(\mathrm{OAB})$ is defined as urinary urgency with or without incontinence, and is often associated with frequency and nocturia in the absence of bladder pathology [1]. Behavior$\mathrm{al}$ and pharmacological treatment (mainly antimuscarinics) are

Corresponding author: M.A. Elbaset (iD https://orcid.org/0000-0001-5669-2999 Urology and Nephrology Center, Mansoura University, Mansoura, Egypt E-mail: abdelbaset.m.i@gmail.com / Tel: +201110160436 Submitted: May 25, 2019 / Accepted after revision: August 23, 2019

(7) $\$$ This is an Open Access article distributed under the terms of the Creative Commons Attribution Non-Commercial License (http://creativecommons.org/licenses/by-nc/4.0/) which permits unrestricted non-commercial use, distribution, and reproduction in any medium, provided the original work is properly cited. 
considered to be the first line of treatment. If behavioral and pharmacological treatment fails, the condition is considered refractory. Adding mirabegron may have opened new therapeutic windows, but this possibility has not yet been established in the long term. Nonetheless, there is a good level of evidence for the use of either antimuscarinics or mirabegron, with emerging data also supporting the use of combination treatment with both classes of drugs [2]. Failure of anticholinergics may be attributed to chronic exposure to antimuscarinics, resulting in reduced expression of $\mathrm{M} 3$ receptors, as opposed to purinergic receptors [3].

Botulinum neurotoxin type A (BTX-A) is now an established line of treatment for refractory $\mathrm{OAB}$ after the failure of medical treatment. Although its mechanism of action is known to involve the neuromuscular junction [4], the effects of BTX-A in the bladder appear more complex, and there is increasing support for a dual mode of action on both efferent and afferent pathways [5]. Intradetrusal injections of BTX-A are followed by significant improvements in incontinence episodes, urodynamic variables, and quality of life (QoL) [6]. However, its effect is temporary and fades within 6 months. In this situation, repeated injections could be offered. However, repeated intradetrusal injections of BTX-A are burdensome and costly, especially in lower-income countries, and BTX-A injections may also have troublesome side effects such as urine retention and infections.

Moreover, there is no firm recommendation according to the American Urological Association/Society of Urodynamics, Female Pelvic Medicine \& Urogenital Reconstruction guidelines regarding which option should be offered in such cases. Posterior tibial nerve stimulation, sacral neuromodulation, open surgery, and combined treatment have shown conflicting results in terms of cost-effectiveness [7]. Furthermore, no studies have evaluated the synchronous use of anticholinergics with BTX-A or metachronous use after the effects of BTX-A fade in cases of refractory idiopathic OAB. Nevertheless, they may have synergetic or additive actions.

Accordingly, there is still a lack of knowledge regarding the effect of BTX-A injections on muscarinic receptor sensitization. Failure of antimuscarinics is related to the reduction of M3 receptor expression (as M3 is the more active component modulating detrusor function) in response to chronic use of antimuscarinics, rather than drug intolerability [3], and previous studies have documented that both anticholinergics and BTX-A may share the same afferent and efferent actions. In addition, previous clinical evidence has shown restoration of vesical urothelial and suburothelial receptors (in terms of number and efficacy) after BTX-A injections, with a possible mechanism being a decrease in the number of suburothelial afferent neurons expressing purinergic and vanilloid receptors $[8,9]$. Therefore, we postulated that restoration of these receptors may sensitize and augment the action of anticholinergics postinjection in cases that became refractory to the initial anticholinergic treatment.

\section{MATERIALS AND METHODS}

Among 132 patients with refractory idiopathic $\mathrm{OAB}$ diagnosed both clinically and with urodynamic studies who were followed up at our outpatient clinic between May 2016 and October 2018, 11 patients were excluded. In total, 121 patients were selected for inclusion in this blind, placebo, waiting-list, controlled study (Fig. 1). All the patients showed initial failure of 10 mg of solifenacin for 3 months (initial solifenacin), after which they were managed by intravesical injections of 100 IU of BTXA. After the effects of BTX-A faded (defined as the return of the overactive bladder symptoms score [OABSS] to near its baseline level before intravesical BTX-A injections), patients were randomly assigned to 2 groups: group A (including 65 patients initially), defined as the study group, in which patients were maintained on $10 \mathrm{mg}$ of solifenacin for 12 weeks, and group B (including 66 patients initially), defined as the control group, in which patients were treated in 2 phases. In the first phase, all patients in group B received placebo treatment for 12 weeks (placebo phase), and in the second phase they received $10 \mathrm{mg}$ of solifenacin for another 6 weeks (subsequent solifenacin). In all phases of the study, patients were blind to the type of treatment.

The exclusion criteria included the use of another anticholinergic drug other than solifenacin, age less than 18 years, neurogenic detrusor overactivity (DO), an active urinary tract infection (UTI) evidenced by positive urine culture, previous solifenacin intolerability, and the development of urine retention after BTX-A injections. After 12 weeks of follow-up, 15 patients in the study group had missed follow-up appointments or had incomplete data at the time of the evaluation. Additionally, 11 patients in the control group were excluded due to an active UTI during the follow-up period, and 5 other patients missed follow-up visits. Therefore, a final total of 100 patients completed the study (50 patients in each arm).

All patients underwent a physical examination, including stress tests and vaginal examinations in females and digital rec- 


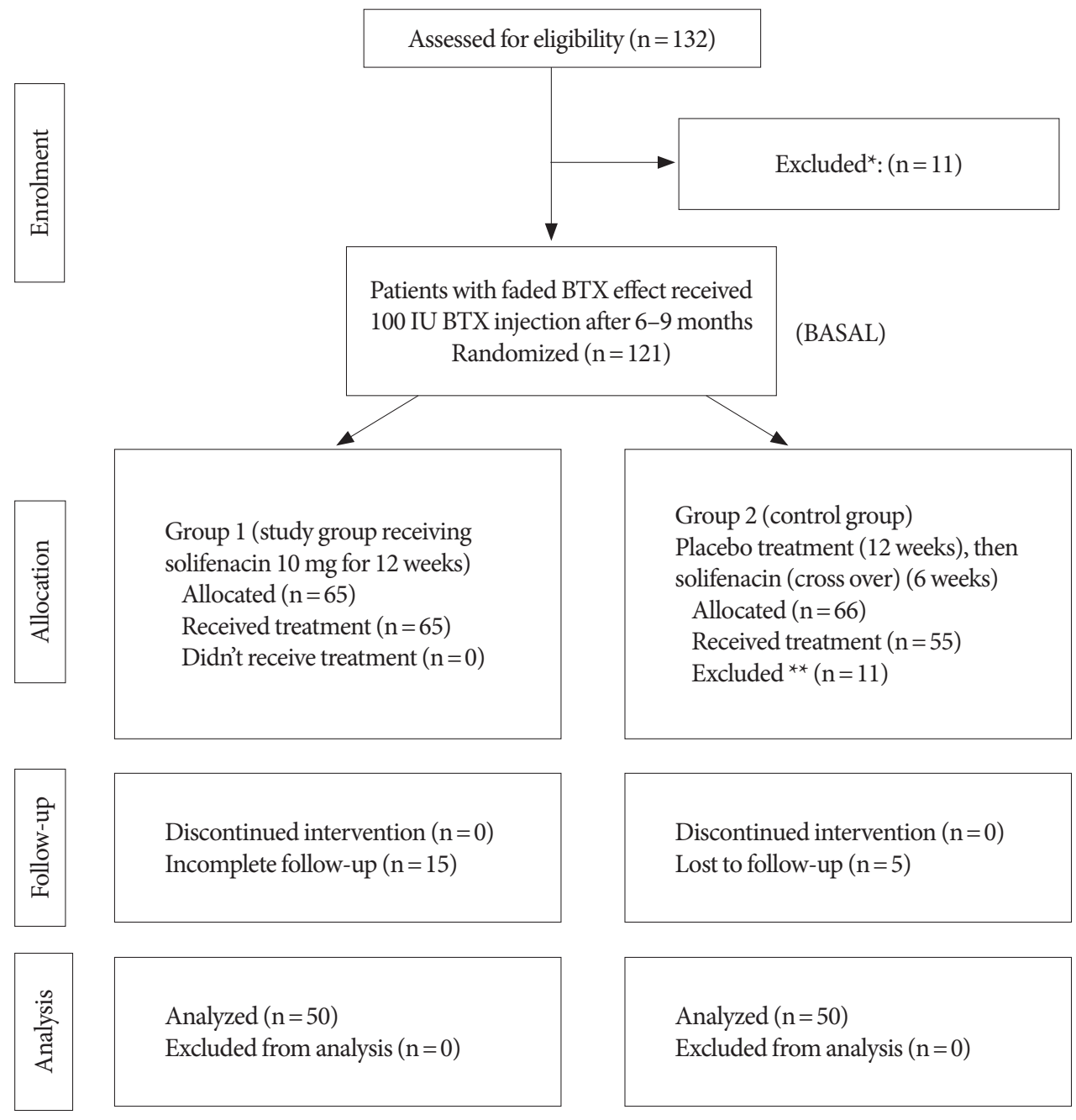

Fig. 1. CONSORT (consolidated standards for reporting of trials) flow chart. BTX, Botulinum neurotoxin. ${ }^{\star}$ Exclusion from the study in view of not meeting inclusion criteria. ${ }^{*}$ Excluded due to active urinary tract infection.

tal examinations in males. A brief neurological examination was conducted. Baseline laboratory investigations (urinalysis and urine culture) and pelvic ultrasound with postvoid residual (PVR) urine volume measurements were conducted. In each study phase, information from the validated OABSS [10] and incontinence QoL (I-QoL) questionnaires [11] were collected by third-party staff not involved in the study. Baseline urodynamic testing consisted of noninvasive flowmetry, a cystomyogram and a pressure-flow study using a standardized research protocol that followed the International Continence Societyrecommended Good Urodynamic Practice Guidelines [12].

Eligible and consenting participants were randomized into the study group and control group on a 1:1 basis with a computer-generated program in blocks of random lengths.
The primary endpoint was assessment of the efficacy of anticholinergic treatment after the effects of BTX-A faded based on the total OABSS after 12 weeks of follow-up. Secondary endpoints included urodynamics parameters (maximum urinary flow rate, PVR, detrusor pressure at the maximum urinary flow rate, number and amplitude of DO, detrusor leak point pressure [DLPP], and maximum cystometric capacity) after 12 weeks of treatment in both study and control (placebo phase) groups. Tertiary objectives included assessment of risk factors of anticholinergic treatment failure in this particular group of patients who received BTX-A. Furthermore, complications were recorded after retreatment with solifenacin $(10 \mathrm{mg})$ in both groups. Moreover, QoL changes after treatment in comparison with baseline were assessed using the I-QoL, which 
contains 3 elements: activation and ability, psychological impact, and socioeconomic impact. Treatment failure was defined as patient dissatisfaction (improvement of less than $50 \%$ in OABSS parameters), the need for intravesical BTX reinjection, or the addition of another anticholinergic drug after 3 months of follow-up.

Data were expressed as mean \pm standard deviation or median (range) according to the distribution. Univariate and multivariate analyses (Cox regression test) to assess risk factors for response to antimuscarinics were done using the chi-square test, Fisher exact test, or independent t-test according to the circumstances. The independent $t$-test was used for assessing I-QoL responses. All statistical tests were carried out using IBM SPSS Statistics ver. 20.0 (IBM Co., Armonk, NY, USA). A P-value of less than 0.05 was considered to indicate statistical significance.

Since no prior study has addressed the use of anticholinergics after the effects of intravesical BTX-A injections fade, the sample size was calculated based on the noninferiority principle. The initial 10 patients at the start of the study were chosen for use in a pilot study, and the difference in treatment success according to improvement in the total OABSS between groups was $20 \%$. This finding was supported by previous studies using solifenacin versus placebo treatment in $\mathrm{OAB}$ without intravesical BTX-A injections $[13,14]$. Based on this difference, 78 patients were required to be $90 \%$ sure that the upper limit of a 1 -sided $95 \%$ confidence interval (CI) (or, equivalently, a $90 \%$ 2-sided CI) would exclude a difference in favor of the study group of more than $10 \%$. Taking into account the high potential discontinuation rate, which we estimated as being as high as $20 \%$, at least a total of 94 patients divided into 47 patients per group were required [15].

Fully informed consent was obtained from all patients after initial exclusion and just before randomization. The study was approved by the Institutional Review Board (IRB No. R/17.07.46) and the study protocol was also recorded at clinicaltrials.gov. There was no conflict of interest and no funding was received. Patients were managed according to the Declaration of Helsinki.

\section{RESULTS}

The study included 121 patients who were maintained on solifenacin $(10 \mathrm{mg})$ initially before any intervention, of whom 100 patients (16 males and 84 females) completed the study. The mean age \pm standard deviation was $32 \pm 10$ years. The median (range) of initial symptom duration before intravesical BTX-A injections was 8 months (1-48 months) in the study group and 12 months (3-34 months) in the control group. The patients started solifenacin $(10 \mathrm{mg})$ treatment 1 month (1-3 months) after fading of the effects of BTX-A. All OABSS questionnaire items before treatment were comparable in both groups at the time of initial treatment. Similarly, urodynamic parameters and PVR were analogous in both groups (Table 1).

After 12 weeks of follow-up, in comparison with the control group during the placebo phase, the study group showed significant improvements in daytime frequency, urgency, urge incontinence, nocturia, and total OABSS $(\mathrm{P}<0.0001)$. Patients in the study group showed a lower frequency of DO than those in the control group $(1.2 \pm 0.3$ vs. $4.7 \pm 1.2, \mathrm{P}<0.0001)$. In addition, the amplitude of DO and DLPP were significantly lower in the study group $(\mathrm{P}=0.03$ and $\mathrm{P}=0.01$, respectively). Cystometric capacity increased significantly in the study group compared to the control group $(\mathrm{P}=0.007)$ (Table 2).

In the control group, comparing patients' reported outcomes during the placebo phase and subsequent solifenacin phase, we observed significant improvements in all OABSS items (urgency, daytime frequency, nocturia, urge incontinence, and total score $)$ in the later stage of treatment $(\mathrm{P}=0.0001, \mathrm{P}=0.003$, $\mathrm{P}=0.01, \mathrm{P}=0.001$, and $\mathrm{P}=0.001$, respectively) (Table 2).

After 6 weeks of solifenacin use in both the control group in the subsequent solifenacin phase and the study group, OABSS and I-QoL improvements were comparable in both groups.

In the study group, the univariate analysis compared patients with failed treatment $(\mathrm{n}=14)(28 \%)$ and patients with a successful outcome $(n=36)(72 \%)$ to assess factors affecting treatment response. Female sex, repeated intravesical BTX-A injections, and greater cystometric capacity were statistically significant predictors of success $(\mathrm{P}=0.001, \mathrm{P}=0.0001$, and $\mathrm{P}=0.002$, respectively). In a multivariate analysis, repeated injections and increased cystometric capacity were independent factors predicting treatment success with relative risks $(95 \% \mathrm{CI})$ of 5.1 $(1.8-5.8)(\mathrm{P}=0.0002)$ and $1.4(1.1-7.8)(\mathrm{P}=0.01)$, respectively (Table 3).

Almost no significant complications took place in either group. The most common complication was dry mouth, which occurred in 8 patients in both groups (study and control) $(<1 \%)$. Two patients in the study group developed high PVR (more than $100 \mathrm{~mL}$ ) and were advised regarding timed voiding. Their PVR decreased significantly by 2 months of follow-up without the need for clean intermittent catheterization.

Regarding I-QoL, in the study group, all QoL elements and 
Table 1. Demographic information of participants and baseline clinical data

\begin{tabular}{|c|c|c|c|}
\hline Variable & Study group $(n=50)$ & Control group $(\mathrm{n}=50)$ & P-value \\
\hline \multicolumn{4}{|l|}{ Demographic data } \\
\hline Age $(y r)^{a)}$ & $32.7 \pm 10.6$ & $32.9 \pm 10.0$ & 0.6 \\
\hline $\begin{array}{l}\text { Sex }^{\text {b) }} \\
\text { Male } \\
\text { Female }\end{array}$ & $\begin{array}{c}8 \\
42\end{array}$ & $\begin{array}{c}8 \\
42\end{array}$ & 0.9 \\
\hline Duration of symptoms before Botox injection $(\mathrm{mo})^{c)}$ & $8(1-48)$ & $12(3-34)$ & 0.4 \\
\hline $\begin{array}{l}\text { OABSS data } \\
\text { Score of urgency } \\
\text { Score of daytime frequency } \\
\text { Score of nocturia } \\
\text { Score of urge incontinence } \\
\text { Pretreatment total OABSS }\end{array}$ & $\begin{array}{r}4.1 \pm 0.9 \\
1.5 \pm 0.6 \\
2.3 \pm 0.7 \\
4.1 \pm 0.9 \\
12.6 \pm 1.8\end{array}$ & $\begin{array}{r}4.2 \pm 0.7 \\
1.5 \pm 0.5 \\
2.4 \pm 0.6 \\
4.2 \pm 0.8 \\
12.8 \pm 1.5\end{array}$ & $\begin{array}{l}0.1 \\
0.3 \\
0.5 \\
0.3 \\
0.1\end{array}$ \\
\hline 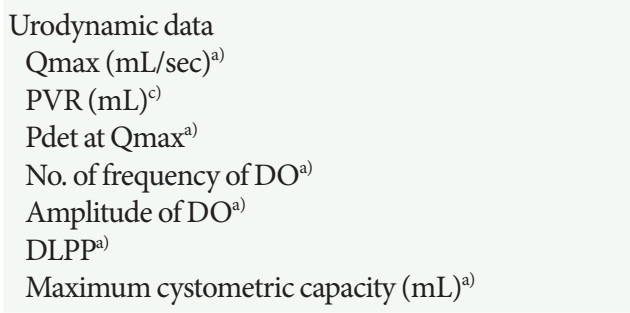 & $\begin{array}{c}26 \pm 8 \\
0(0-75) \\
24.2 \pm 10.4 \\
4.2 \pm 1.3 \\
51.6 \pm 20.8 \\
69.0 \pm 15.3 \\
350 \pm 106\end{array}$ & $\begin{array}{c}23.8 \pm 8.2 \\
0(0-85) \\
24.3 \pm 9.7 \\
4.6 \pm 1.3 \\
52.0 \pm 21.4 \\
71.0 \pm 16.7 \\
331 \pm 103\end{array}$ & $\begin{array}{l}0.3 \\
0.6 \\
0.8 \\
0.3 \\
0.2 \\
0.2 \\
0.08\end{array}$ \\
\hline $\begin{array}{l}\text { I-QoL scores } \\
\text { ALB score } \\
\text { PSY score } \\
\text { SE score } \\
\text { Total score }^{\text {a) }}\end{array}$ & $\begin{array}{r}11.9 \pm 3.2 \\
11.6 \pm 2.3 \\
6.4 \pm 1.5 \\
29.9 \pm 1.9\end{array}$ & $\begin{array}{r}11.8 \pm 3.0 \\
11.7 \pm 2.2 \\
6.5 \pm 1.6 \\
29.3 \pm 1.8\end{array}$ & $\begin{array}{l}0.8 \\
0.8 \\
0.7 \\
0.3\end{array}$ \\
\hline
\end{tabular}

Values are presented as mean \pm standard deviation or median (range).

OABSS, overactive bladder symptoms score; Qmax, maximum flow rate; PVR, postvoid residual; Pdet at Qmax, detrusor pressure at maximum flow rate; DO, detrusor overactivity; DLPP, detrusor leak point pressure; I-QoL, incontinence quality of life; ALB, activation and ability; PSY, psychological; SE, socioeconomic.

a) t-test. ${ }^{\text {b) }}$ Chi-square. ${ }^{c}$ Mann-Whitney test.

the total score improved significantly compared with placebo treatment in the control group. In different phases of treatment (initial solifenacin, 6 months after BTX-A injection [baseline], and subsequent solifenacin treatment) subsequent solifenacin treatment achieved a higher response than other phases. In the control group, all I-QoL elements and the total score improved significantly with subsequent solifenacin treatment, in contrast to the placebo treatment and initial solifenacin (Table 2) (Fig. 2).

\section{DISCUSSION}

Refractory $\mathrm{OAB}$ management still presents a dilemma. In most cases, OAB symptoms can be reduced, leading to improvements in patients' QoL. It is well established that patients who do not respond to conservative behavioral treatment can use anticholinergics as a second line of treatment.
In $\mathrm{OAB}$, it is known that hyperactive acetylcholine (Ach) secretion occurs by both neuronal and non-neuronal sources (urothelium). Furthermore, the increase in the sensitivity of the detrusor smooth muscle to Ach provokes local contractions of the detrusor (micromotion). These local contractions in the bladder wall produce afferent signals, precipitating urgency and DO [16].

Antimuscarinics suppress local contractions in the detrusor, eventually reducing bladder afferent activity by inhibiting the action of Ach on muscarinic receptors. M2 receptors are the most common receptors within the bladder wall, but M3 is a more active component modulating detrusor function [17]. In using antimuscarinics, $\mathrm{DO}$ is decreased by a dual mechanism of action in both efferent and afferent neuronal pathways [18]. Antimuscarinics may fail due to causes related to patient intolerability, inadequate dose titration, or side effects [19]. Further- 
Table 2. OABSS, urodynamics, and I-QoL changes in both groups posttreatment

\begin{tabular}{|c|c|c|c|c|c|}
\hline Variable & $\begin{array}{l}\text { Study group } \\
\quad(\mathrm{n}=50)\end{array}$ & $\begin{array}{l}\text { Control group } \\
\text { (placebo phase) } \\
(n=50)\end{array}$ & $\begin{array}{c}\text { Control group } \\
\text { (subsequent } \\
\text { solifenacin treatment) } \\
(\mathrm{n}=50)\end{array}$ & $\mathrm{P}_{1 \text {-value }}$ & $\mathrm{P}_{2}$-value \\
\hline \multicolumn{6}{|l|}{ OABSS data } \\
\hline Score of urgency ${ }^{a)}$ & $1.9 \pm 0.5$ & $4.2 \pm 0.8$ & $2.8 \pm 0.7$ & $<0.0001$ & 0.0001 \\
\hline Score of daytime frequency ${ }^{a)}$ & $0.9 \pm 0.4$ & $2.1 \pm 0.6$ & $1.3 \pm 0.6$ & $<0.0001$ & 0.003 \\
\hline Score of nocturia ${ }^{\text {a) }}$ & $0.8 \pm 0.3$ & $2.2 \pm 0.8$ & $1.9 \pm 0.6$ & $<0.0001$ & 0.01 \\
\hline Score of urge incontinence ${ }^{a}$ & $1.3 \pm 0.6$ & $4.3 \pm 0.7$ & $2.5 \pm 0.7$ & $<0.0001$ & 0.001 \\
\hline Total OABSS ${ }^{\mathrm{a})}$ & $6 \pm 1.8$ & $11.2 \pm 3.8$ & $8.2 \pm 2.5$ & $<0.0001$ & 0.001 \\
\hline \multicolumn{6}{|l|}{ I-QoL changes } \\
\hline ALB score $e^{\mathrm{a})}$ & $28 \pm 2.9$ & $8.2 \pm 0.6$ & $25 \pm 2.6$ & $<0.0001$ & 0.08 \\
\hline PSY score ${ }^{a)}$ & $30.2 \pm 3.8$ & $9.1 \pm 0.3$ & $21.5 \pm 3.6$ & $<0.0001$ & 0.03 \\
\hline SE score ${ }^{a)}$ & $13.5 \pm 2.5$ & $5 \pm 0.1$ & $11.5 \pm 3$ & $<0.0001$ & 0.1 \\
\hline Total score ${ }^{a}$ & $68.9 \pm 11$ & $22.3 \pm 0.7$ & $58 \pm 11$ & $<0.0001$ & 0.04 \\
\hline \multicolumn{6}{|l|}{ Urodynamic data } \\
\hline $\mathrm{Qmax}(\mathrm{mL} / \mathrm{sec})^{\mathrm{b})}$ & $25(12-44)$ & $23(6-62)$ & - & 0.3 & - \\
\hline $\operatorname{PVR}(\mathrm{mL})^{\mathrm{b})}$ & $15(0-100)$ & $10(0-60)$ & - & 0.9 & - \\
\hline Pdet at Qmax ${ }^{\mathrm{a})}$ & $65.7 \pm 30.8$ & $62.5 \pm 0.9$ & - & 0.2 & - \\
\hline No. of frequency of $\mathrm{DO}^{\mathrm{a})}$ & $1.2 \pm 0.3$ & $5.6 \pm 1.2$ & - & $<0.0001$ & - \\
\hline Amplitude of $\mathrm{DO}^{\mathrm{a})}$ & $13.8 \pm 3.9$ & $19.3 \pm 6.4$ & - & 0.03 & - \\
\hline DLPP $^{\mathrm{a})}$ & $43.7 \pm 7.4$ & $59.9 \pm 7.6$ & - & 0.01 & - \\
\hline Maximum cystometric capacity $(\mathrm{mL})^{\mathrm{a})}$ & $376 \pm 92.5$ & $328 \pm 94$ & - & 0.007 & - \\
\hline
\end{tabular}

Values are presented as mean \pm standard deviation or median (range).

OABSS, overactive bladder symptoms score; I-QoL, incontinence quality of life; Qmax, maximum flow rate; PVR, postvoid residual; Pdet at Qmax, detrusor pressure at maximum flow rate; DO, detrusor overactivity; DLPP, detrusor leak point pressure; ALB, activation and ability; PSY, psychological; SE, socioeconomic.

$\mathrm{P}_{1}$-value: value between the study group and the control group (placebo phase). $\mathrm{P}_{2}$-value: value between the placebo phase and the subsequent solfenacin phase in the control group.

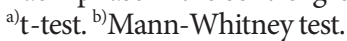

Table 3. Factors affecting response (reinjections of BTX-A) to anticholinergics after intravesical BTX injections in the study group after 12 weeks of follow-up

\begin{tabular}{|c|c|c|c|c|c|}
\hline \multirow[b]{2}{*}{ Variable } & \multicolumn{3}{|c|}{ Univariate analysis } & \multicolumn{2}{|c|}{ Multivariate analysis ${ }^{\mathrm{d})}$} \\
\hline & $\begin{array}{l}\text { BTX-A reinjection } \\
\quad(\mathrm{n}=14)\end{array}$ & $\begin{array}{c}\text { No BTX-A } \\
\text { reinjection }(n=36)\end{array}$ & P-value & OR $(95 \% \mathrm{CI})$ & P-value \\
\hline Age (yr) & $32 \pm 8$ & $31 \pm 10$ & $0.4^{\text {a) }}$ & & \\
\hline $\begin{array}{l}\text { Sex } \\
\text { Male } \\
\text { Female }\end{array}$ & $\begin{array}{r}1 \\
13\end{array}$ & $\begin{array}{r}7 \\
29\end{array}$ & $0.001^{c)}$ & $4.3(0.8-8.3)$ & 0.08 \\
\hline $\begin{array}{l}\text { Previous BTX injection times } \\
\text { Once } \\
\text { Twice } \\
\text { Three times }\end{array}$ & $\begin{array}{l}9 \\
3 \\
2\end{array}$ & $\begin{array}{r}12 \\
16 \\
8\end{array}$ & $0.0001^{\mathrm{b})}$ & $5.1(1.2-5.7)$ & 0.003 \\
\hline Pretreatment total OABSS & $11.5 \pm 2$ & $11.7 \pm 1.6$ & $0.6^{\mathrm{a})}$ & - & - \\
\hline No. of DO & $3.3 \pm 1.5$ & $3.9 \pm 1.3$ & $0.09^{\mathrm{a})}$ & - & - \\
\hline Amplitude of DO & $50 \pm 23$ & $47 \pm 22$ & $0.1^{\text {a) }}$ & - & - \\
\hline Maximum cystometric capacity (mL) & $300 \pm 106$ & $378 \pm 76$ & $0.002^{\mathrm{a})}$ & $1.4(1.1-7.8)$ & 0.01 \\
\hline DLPP & $61 \pm 25$ & $63 \pm 24$ & $0.07^{\mathrm{a})}$ & - & - \\
\hline
\end{tabular}

Values are presented as mean \pm standard deviation or number unless otherwise indicated.

BTX-A, Botulinum neurotoxin type A; OR, odds ratio; CI, confidence interval; OABSS, overactive bladder symptoms score; DO, detrusor overactivity; DLPP, detrusor leak point pressure.

a) -test. ${ }^{\text {b) }}$ Chi-square. ${ }^{\text {c) }}$ Fisher's exact test. ${ }^{\text {d) }}$ Cox regression analysis. 

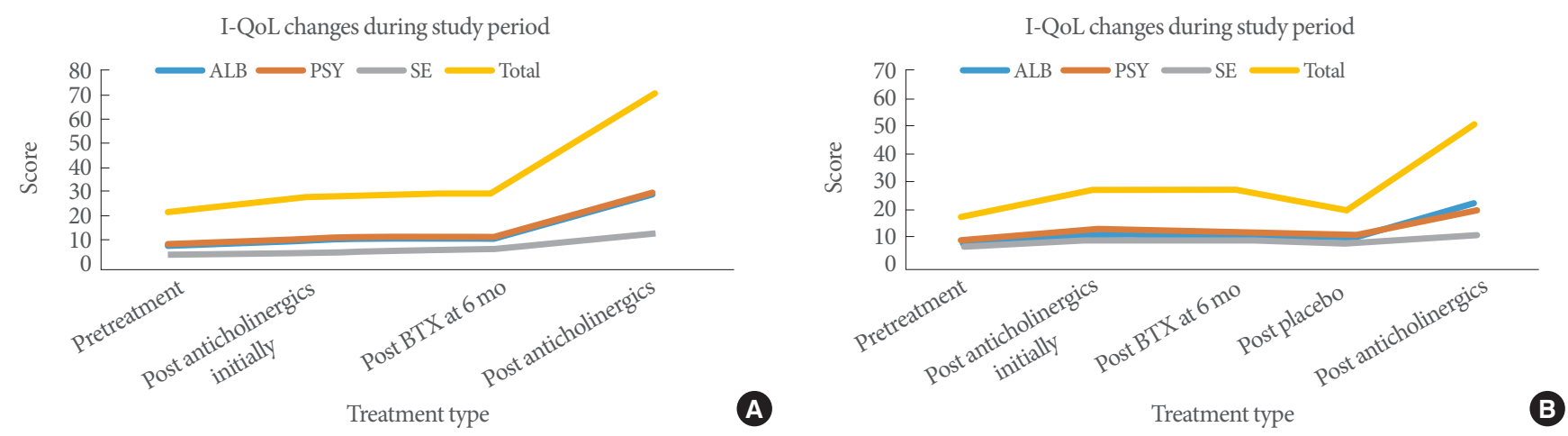

Fig. 2. Incontinence quality of life (I-QoL) score differences at different stages of treatment in the study group (A) and the control group (B). ALB, activation and ability; PSY, psychological; SE, socioeconomic; BTX, botulinum toxin.

more, the reduction of $\mathrm{M} 3$ receptor expression in response to the chronic use of antimuscarinics provides another explanation for such failure.

In cases resistant to anticholinergic treatment, intradetrusal BTX-A injections could be offered [20]. Chapple et al. [21] documented that BTX-A (100 U) treatment was associated with clinically relevant reductions in all OAB symptoms compared with placebo treatment. These benefits were maintained briefly for a mean of 6-9 months after treatment [22]. After the fading of the effects of BTX-A effects, patients may prefer to change to another line of treatment, as documented by the finding of Hashim et al. that only $9 \%$ of patients preferred BTXA reinjection, which may have been due to higher costs and side effects such as urinary retention and UTIs [23]. Based on previous studies, both anticholinergics and BTX-A may share the same afferent action, as suggested by clinical findings and immunohistochemical assays assessing the affinity and number of intravesical receptors, which showed evidence that BTX-A injections could restore the number and efficacy of intravesical urothelial and suburothelial receptors [8]. In neurogenic DO [24], it has been documented that concomitant use of both treatments improved OAB symptoms, increased time to reinjection, and decreased both the dose and frequency of anticholinergic use.

In the $\mathrm{ABC}$ trial, which tested the effects of solifenacin (5 or $10 \mathrm{mg}$ ) in comparison with BTX-A for 6 months, both groups showed similar reductions in daily episodes of urge incontinence [18]. Furthermore, many authors [13,25] found statistically significant improvements at 12 weeks of follow-up regarding urgency, incontinence, and frequency in patients who used solifenacin once daily compared with a placebo group. Additionally, notable improvements in QoL domains were correlat- ed with improvements in nocturia symptoms. Interestingly in our study, patients who were refractory to solifenacin at the initial treatment before shifting to BTX-A developed responsiveness again, with an improvement of all OABSS items and overall score at 12 weeks of follow-up in the study group. Moreover, in the control group, all OABSS items and the total score improved after the subsequent phase of solifenacin treatment for 6 weeks relative to the phase of placebo treatment. Furthermore, improved urodynamic parameters (decreased frequency and amplitude of DO, DLPP, and increased cystometric capacity) in the study group were noted. In the assessment of factors affecting treatment response, repeated intravesical BTX-A injections and increased cystometric capacity were independent factors that predicted a successful response. A possible explanation for this is that intravesical BTX-A injections and anticholinergics increase bladder capacity, volume at first reflex detrusor contraction, and bladder compliance and decrease detrusor pressure during bladder filling and voiding [26]. These factors could explain why solifenacin may again yield a response after initial failure, as repeated BTX-A injections may result in increased bladder capacity and restoration of the normal numbers and function of M3 receptors, potentially restoring patients' responsiveness to anticholinergic drugs. We did not include patients in the control group after subsequent solifenacin treatment in final statistical analysis, as they were maintained on active treatment for only 6 weeks.

As a chronic, unbearable condition, OAB harms QoL, including social, physical, psychological, occupational, and sexual domains. Many patients stopped their social and physical activities and suffered from psychological stress. It was reported that once daily solifenacin treatment was associated with significant improvements in QoL compared with placebo [27]. In a large 
clinical study (VOLT) [28], it was reported that solifenacin improved all subscales of QoL. Furthermore, Anger [29] documented in a metanalysis of 4 previous studies that BTX-A treatment improved QoL scores, as shown by a 15-point drop in Urinary Distress Inventory scores compared to placebo-injected patients. In our study, improved OABSS co-occurred with significant improvements in I-QoL items and the total score in response to the usage of solifenacin after fading of the effects of BTX-A in the study group in comparison with initial solifenacin treatment and baseline findings. Additionally, the I-QoL items improved in the control group after the crossover treatment period in the subsequent solifenacin phase for 6 weeks after the placebo treatment phase.

Insignificant complications occurred in both groups. Dry mouth was the most relevant complication. Two patients in the study group developed urinary retention, as shown by an elevated PVR, and were treated conservatively.

The limitations of this study include the possibility of bias by including patients who were maintained previously on solifenacin before intravesical BTX-A injections. However, this might provide insights into changes in the effects of a single fixed treatment course. Using the noninferiority principle in sample size calculation had some disadvantages; it would be necessary to have a larger number of patients with strict compliance to treatment with longer-term follow-up to prove the efficacy of treatment, and the noninferiority principle needs only 1 measurable outcome to calculate the sample size. However, the most important advantage of a noninferiority trial is that it provides clear evidence of the efficacy of treatment. Despite the relatively small sample size, we were able to detect factors affecting treatment response, as most clearly shown by the sex difference between treatment responders and non-responders, especially in the univariate analysis. A larger study population is needed to confirm our results. It would also be helpful to biopsy bladder tissue and quantify receptor expression before and after treatment to better delineate the mechanism action and to establish the interactions between these treatments.

In patients with refractory idiopathic $\mathrm{OAB}$, reuse of anticholinergics could be an effective treatment option in patients after fading of the effects of BTX-A. The use of this line of treatment can delay or eliminate the need for reinjections of BTX-A. Repeated intravesical BTX-A injections and increased cystometric capacity could affect the treatment response.

\section{AUTHOR CONTRIBUTION STATEMENT}

- Full access to all the data in the study and takes responsibility for the integrity of the data and the accuracy of the data analysis: $M A E, D E T, A S H, M H Z, A A S$

- Study concept and design: $M A E, D E T$

- Acquisition of data: MAE

- Analysis and interpretation of data: $M A E, D E T$

- Drafting of the manuscript: $M A E$

- Critical revision of the manuscript for important intellectual content: DET, ASH, AAS

- Statistical analysis: $M H Z$

- Study supervision: $A S H, A A S$

\section{REFERENCES}

1. Abrams P, Andersson KE, Buccafusco JJ, Chapple C, de Groat WC, Fryer AD, et al. Muscarinic receptors: their distribution and function in body systems, and the implications for treating overactive bladder. Br J Pharmacol 2006;148:565-78.

2. Apostolidis A, Averbeck MA, Sahai A, Rahnama’i MS, Anding R, Robinson D, et al. Can we create a valid treatment algorithm for patients with drug resistant overactive bladder $(\mathrm{OAB})$ syndrome or detrusor overactivity (DO)? Results from a think tank (ICI-RS 2015). Neurourol Urodyn 2017;36:882-93.

3. Uvin P, Boudes M, Menigoz A, Franken J, Pinto S, Gevaert T, et al. Chronic administration of anticholinergics in rats induces a shift from muscarinic to purinergic transmission in the bladder wall. Eur Urol 2013;64:502-10.

4. Dolly O. Synaptic transmission: inhibition of neurotransmitter release by botulinum toxins. Headache 2003;43 Suppl 1:S16-24.

5. Apostolidis A, Dasgupta P, Fowler CJ. Proposed mechanism for the efficacy of injected botulinum toxin in the treatment of human detrusor overactivity. Eur Urol 2006;49:644-50.

6. Mangera A, Andersson KE, Apostolidis A, Chapple C, Dasgupta P, Giannantoni A, et al. Contemporary management of lower urinary tract disease with botulinum toxin A: a systematic review of botox (onabotulinumtoxinA) and dysport (abobotulinumtoxinA). Eur Urol 2011;60:784-95.

7. Gormley EA, Lightner DJ, Burgio KL, Chai TC, Clemens JQ, Culkin DJ, et al. Diagnosis and treatment of overactive bladder (non-neurogenic) in adults: AUA/SUFU guideline. J Urol 2012; 188(6 Suppl):2455-63.

8. Datta SN, Roosen A, Pullen A, Popat R, Rosenbaum TP, Elneil S, et al. Immunohistochemical expression of muscarinic receptors in 
the urothelium and suburothelium of neurogenic and idiopathic overactive human bladders, and changes with botulinum neurotoxin administration. J Urol 2010;184:2578-85.

9. Leippold T, Reitz A, Schurch B. Botulinum toxin as a new therapy option for voiding disorders: current state of the art. Eur Urol 2003; 44:165-74.

10. Elbaset MA, Hashem A, Taha DE, Zahran MH, El-Hefnawy AS. Validation of the Arabic linguistic version of the overactive bladder symptoms score questionnaire. Arab J Urol 2019:1-5. https://doi.or g/10.1080/2090598X.2019.1627061

11. Patrick DL, Martin ML, Bushnell DM, Yalcin I, Wagner TH, Buesching DP. Quality of life of women with urinary incontinence: further development of the incontinence quality of life instrument (I-QOL). Urology 1999;53:71-6.

12. Schäfer W, Abrams P, Liao L, Mattiasson A, Pesce F, Spangberg A, et al. Good urodynamic practices: uroflowmetry, filling cystometry, and pressure-flow studies. Neurourol Urodyn 2002;21:261-74.

13. Chapple CR, Rechberger T, Al-Shukri S, Meffan P, Everaert K, Huang M, et al. Randomized, double-blind placebo- and tolterodine-controlled trial of the once-daily antimuscarinic agent solifenacin in patients with symptomatic overactive bladder. BJU Int 2004;93:303-10.

14. Vardy MD, Mitcheson HD, Samuels TA, Wegenke JD, ForeroSchwanhaeuser S, Marshall TS, et al. Effects of solifenacin on overactive bladder symptoms, symptom bother and other patient-reported outcomes: results from VIBRANT - a double-blind, placebo-controlled trial. Int J Clin Pract 2009;63:1702-14.

15. Bowalekar SK. Non-inferiority and equivalence trials: Need for a standardized process. Perspect Clin Res 2011;2:115-8.

16. Yamaguchi O. Latest treatment for lower urinary tract dysfunction: therapeutic agents and mechanism of action. Int J Urol 2013;20:2839.

17. Toozs-Hobson P, Elnaqa A. Detrusor overactivity--an update. BJOG 2004;111 Suppl 1:53-6.

18. Visco AG, Brubaker L, Richter HE, Nygaard I, Paraiso MF, Menefee SA, et al. Anticholinergic therapy vs. onabotulinumtoxina for urgency urinary incontinence. N Engl J Med 2012;367:1803-13.

19. Wein AJ. Diagnosis and treatment of the overactive bladder. Urology 2003;62(5 Suppl 2):20-7.

20. Marcelissen TA, Rahnama’i MS, Snijkers A, Schurch B, De Vries P. Long-term follow-up of intravesical botulinum toxin-A injections in women with idiopathic overactive bladder symptoms. World J Urol 2017;35:307-11.

21. Chapple C, Sievert KD, MacDiarmid S, Khullar V, Radziszewski P, Nardo C, et al. OnabotulinumtoxinA 100 U significantly improves all idiopathic overactive bladder symptoms and quality of life in patients with overactive bladder and urinary incontinence: a randomised, double-blind, placebo-controlled trial. Eur Urol 2013; 64:249-56.

22. Chohan N, Hilton P, Brown K, Dixon L. Efficacy and duration of response to botulinum neurotoxin A (onabotulinumA) as a treatment for detrusor overactivity in women. Int Urogynecol J 2015; 26:1605-12.

23. Hashim H, Beusterien K, Bridges JF, Amos K, Cardozo L. Patient preferences for treating refractory overactive bladder in the UK. Int Urol Nephrol 2015;47:1619-27.

24. Grise P, Ruffion A, Denys P, Egon G, Chartier Kastler E. Efficacy and tolerability of botulinum toxin type $\mathrm{A}$ in patients with neurogenic detrusor overactivity and without concomitant anticholinergic therapy: comparison of two doses. Eur Urol 2010;58:759-66.

25. Cardozo L, Lisec M, Millard R, van Vierssen Trip O, Kuzmin I, Drogendijk TE, et al. Randomized, double-blind placebo controlled trial of the once daily antimuscarinic agent solifenacin succinate in patients with overactive bladder. J Urol 2004;172(5 Pt 1):1919-24.

26. Apostolidis A, Rahnama’i MS, Fry C, Dmochowski R, Sahai A. Do we understand how botulinum toxin works and have we optimized the way it is administered to the bladder? ICI-RS 2014. Neurourol Urodyn 2016;35:293-8.

27. Toglia MR, Serels SR, Laramée C, Karram MM, Nandy IM, Andoh $\mathrm{M}$, et al. Solifenacin for overactive bladder: patient-reported outcomes from a large placebo-controlled trial. Postgrad Med 2009;121:151-8.

28. Garely AD, Kaufman JM, Sand PK, Smith N, Andoh M. Symptom bother and health-related quality of life outcomes following solifenacin treatment for overactive bladder: the VESIcare Open-Label Trial (VOLT). Clin Ther 2006;28:1935-46.

29. Anger JT, Weinberg A, Suttorp MJ, Litwin MS, Shekelle PG. Outcomes of intravesical botulinum toxin for idiopathic overactive bladder symptoms: a systematic review of the literature. J Urol 2010;183:2258-64 